\title{
New reference materials and assessment of matrix effects for SIMS analyses of oxygen isotopes in gamet
}

Alice Vho (1)*, Daniela Rubatto (1,2), Benita Putlitz (2) and Anne-Sophie Bouvier (2)

(1) Institute of Geological Sciences, University of Bem, Bem, CH-3012, Switzerland

(2) Institute of Earth Sciences, University of Lausanne, Lausanne, CH-1015, Switzerland

*Corresponding a uthor e-mail: a lice.vho@geo.unibe.ch

Accurate ion microprobe analysis of oxygen isotope ratios in gamet requires appropriate reference materials to correct for instrumental mass fractionation that partly depends on the gamet chemistry (matrix effect). The matrix effect comelated with grossular, spessartine and andradite components was characterised for the Cameca IMS 1280HR at the SwissiMS laboratory based on 17 reference gamet samples. The comelations fit a second degree polynomial with maximum bias of ca. $4 \%$, $2 \%$ and $8 \%$ respectively. While the grossular composition range $0-25 \%$ is adequately covered by available reference materials, there is a paucity of them for intermediate compositions. We characterize three new gamet reference materials GRS2, GRS JH2 and CAP02 with a grossular content of $88.3 \pm 1.2 \%(2 \mathrm{sd}), 83.3 \pm 0.8 \%$ and $32.5 \pm 3.0 \%$ respectively. Their microscale homogeneity in oxygen isotope composition was evaluated by multiple SIMS sessions. The reference $\delta^{18} \mathrm{O}$ value was determined by $\mathrm{CO}_{2}$ laser fluorination $\left(\delta^{18} \mathrm{O}_{\llcorner\mathrm{F}}\right)$. GRS2 has $\delta^{18 O_{\mathrm{vF}}}=8.01 \pm 0.10 \%$ (2sd) and repeatability within each SIMS session of 0.30 - $0.60 \%$ (2sd), GRS-J H2 has $\delta^{18} 0_{\text {tF }}$ 


\section{$=18.70 \pm 0.08 \%$ and repeatability of $0.24-0.42 \%$ and CAPO2 has $\delta^{18} O_{t F}=4.64 \pm$ $0.16 \%$ and repeatability of $0.40-0.46 \%$ o}

Significant advances in stable isotope analyses by secondary ion mass spectrometer (SIMS) in the last decades have led to an improvement in precision (down to $\pm 0.1-0.3 \%$, 2sd) and spatial resolution (down to $<10 \mu \mathrm{m})$ (e.g., Eiler et al. 1997; Riciputi et al. 1998; Kita et al. 2009; Ickert and Stem 2013; Martin et al. 2014; Regier et al. 2018). The great advantage of this in situ technique is the capability of resolving variations within single mineral grains and analysing fine-grained minerals with preservation of textural information. The principal limitation remains the instrumental mass fractionation dependent upon sample chemistry, temed the matrix effect (Eiler et al. 1997). Thus a ccuracy strongly relies on reference materials that are asclose as possible to the chemistry of the unknowns.

Gamet is a key mineral used in metamomhic petrology to constrain pressure, temperature and time paths. It commonly records different stages of the rock evolution as distinct mineral zones, which oxygen isotope compositions may assist to reconstruct fluid-rock interaction and fluid sources over the metamorphic evolution of the host rock (e.g., Chamberlain and Conrad 1991; Erico et al. 2013; Page et al. 2013; Martin et al. 2014; Rubatto and Angiboust 2015; Quinn et al. 2017). Gamet is a solid solution between five main end-members: grossular ( $\mathrm{Grs}, \mathrm{Ca}_{3} \mathrm{Al}_{2} \mathrm{Si}_{3} \mathrm{O}_{12}$ ), pyrope (Prp, $\left.\mathrm{Mg}_{3} \mathrm{Al}_{2} \mathrm{Si}_{3} \mathrm{O}_{12}\right)$, a Imandine ( $\mathrm{Alm}, \mathrm{Fe}_{3} \mathrm{Al}_{2} \mathrm{Si}_{3} \mathrm{O}_{12}$ ), spessartine (Sps, $\mathrm{Mn}_{3} \mathrm{Al}_{2} \mathrm{Si}_{3} \mathrm{O}_{12}$ ) and andradite ( $\mathrm{And}, \mathrm{Ca}_{3} \mathrm{Fe}^{3+}{ }_{2} \mathrm{Si}_{3} \mathrm{O}_{12}$ ). It has been demonstrated that grossular, andradite and spessartine components can be correlated with significant mass fractionation (Vielzeuf et al. 2005a; Page et al. 2010; Ickert and Stem 2013; Martin et al. 2014). In this study, we present an empinical model that relates mass bias to grossular, andradite and spessartine abundance in gamet for the Cameca IMS $1280 \mathrm{HR}$ at the 
SwissSIMS la boratory (University of Lausa nne). We a dditionally consider the variation of this sc heme over time and compare it with results from previous stud ies.

To adequately quantify the matrix effect for minerals with complex chemistry as gamet, an extensive suite of reference materials covering a wide compositional range is required (Page et al. 2010; Raimondo et al. 2012; Ickert and Stem 2013; Martin et al. 2014). Along the grossular compositional range, previously characterized reference materials have composition mostly between Grs $=0-25 \%$ and a few of them in the range Grs = $85-95 \%$ (Page et al. 2010; Martin et al. 2014). Such high-grossular compositions are typical for themally and regionally metamorphosed impure calcareous rocks, rocks that have undergone calcium metasomatism (e.g., rodingites) and metamorphosed Ca-rich basalts (Deer et al. 1992). To supplement the available reference materials and improve the accuracy of the correction for high and intermediate grossular compositions, new gamet samples GRS2, GRS-J H2 and CAP02 suitable as reference materials for SIMS oxygen isotope a nalysis a re introduced in this study.

\section{$\underline{\text { Reference materials used for matrix effect evaluation }}$}

To perform accurate matrix corrections for oxygen isotope measurements in gamet, 13 previously investigated gamet reference materials and 3 newly characterised gamet samples were used in this study to cover a large range in grossular, andradite and spessartine compositional space (Figure 1). To cover the grossular compositional range, reference materia ls UWG2 (Valley et al. 1995), 10691 (Kohn and Valley 1998; Page et al. 2010), B114, PRP-AA, PRP-AK, 2 B3 (Vielzeuf et al. 2005a,b), Kakanui (Gonza ga et al. 2010; Urosevic et al. 2018), a s well as GRS2 , GRSJH2 and CAP02 (this study) were analysed. To cover the spessartine compositional 
range, reference materials were UWG2 (Valley et al. 1995), 2 B3 (Vielzeuf et al. 2005a,b), SPEBH, GRTIA (Martin et al. 2014) and ErrRED (Urosevic et al. 2018). Reference materia Is to cover the grossular-andradite join were LEW10, LEW6, 92-W2, 10691 (Kohn and Valley 1998; Page et al. 2010), 2B3 (Vielzeuf et al. 2005a,b) and AndRG (Martin et al. 2014).

Gamet crysta ls GRS2 and GRS-JH2 were bought at a mineral fair and their likely provenance is Afghanistan. GRS2 is a crystal of $\sim 0.4 \mathrm{~g}$ light brown in colour, GRS-J H2 is a crystal of $\sim 1.4 \mathrm{~g}$ dark orange-brown in colour. CAPO2 is a light pink gamet separated from an eclogite found in the mafic-ultramafic lens of Capoli in the Central Swiss Alps (Brouwer et al. 2005). Gamet constitutes ca. $70 \%$ of the sample that also conta ins omphacite and accessory rutile.

\section{Analytical methods}

\section{Sample preparation}

Previously characterized gamet reference materials were crushed by hand, cast in 3 epoxy disks with dia meter of $25 \mathrm{~mm}$, each one containing multiple grains or grain fragments of the available reference materials for the grossular, andradite and spessartine compositional ranges. These three mounts a re referred to as GRT-GRS, G RT-AND a nd GRT-SPS respec tively. Fra gments of ga met crystals G RS-J H2 and GRS2 were mounted in GRT-GRS together with previously characterized reference materials. Each mount contains several grains of UWG2 to be used as intemal standard. The samples were located in the central $10 \mathrm{~mm}$ of the mount to avoid possible sample location effects (Peres et al. 2013). 
CAP02 sample was disaggregated using a Selfrag apparatus at the Institute of Geological Sciences, University of Bem, which produced a high yield of intact mineral grains by high-voltage pulsing, and sieved to select the grain fraction between 125 and $500 \mu \mathrm{m}$. Around 40 inclusion-free gamet crystals of $150-250 \mu \mathrm{m}$ size were hand-picked and mounted in an epoxy disks with diameter of $25 \mathrm{~mm}$ together with multiple grains of UWG 2 as intemal standard and few fragments of the gamet GRS-J H2. The samples were located in the central $10 \mathrm{~mm}$ of the mount to avoid possible sample location effects (Peres et al. 2013).

All the epoxy mounts were ground to expose the grains and then polished with 6,3 and $1 \mu \mathrm{m}$ diamond paste. The topography of the mounts was checked with a light mic roscope and was less than $5 \mu \mathrm{m}$ in all cases. All the mounts were carefully cleaned and coated with gold prior to SIMS analysis. The mount containing CAP02 and the mount GRT-GRS containing GRS2 and GRS-J H2 were subsequently polished to remove gold coating and coated with carbon prior to EPMA a nalysis.

\section{Eectron mic roprobe}

Major element composition of the gamet CAP02, GRS2 and GRS-JH2 was determined by electron probe microanalysis (EPMA) using a JEOL JXA-8200 superprobe at the Institute of Geological Sciences, University of Bem. Gamet was analysed in point beam mode with an accelerating potential of $15 \mathrm{kV}$ and $20 \mathrm{nA}$ beam current. The counting time was $20 \mathrm{~s}$ on peak and $10 \mathrm{~s}$ off-peak. For the calculation of mineral fomulae from chemical analyses, almandine, pyrope, grossular, spessartine, andradite and Ca-Ti gamet end-members were taken into consideration. $\mathrm{Fe}^{2+} / \mathrm{Fe}^{3+}$ was estimated by charge balance, assuming no site vacancies or $\mathrm{OH}$ substitution. Mineral stoic hiometry was determined by norma lizing 
to 12 oxygens (fomula calculation from the Excel spreadsheet Mineral Nomalization v.16, John Brady, Smith College and Dexter Perkins, University of North Dakota, https://serc.ca leton.edu/research_education/equilibria/minera lformula erec a lc ula ti on.html). Results are reported in Table 1.

\section{Oxygen isotope composition by $\mathrm{CO}_{2}$ laser fluorination}

Oxygen isotope compositions of GSR2, GRS-J H2 and CAP02 were determined at the stable isotope laboratory of the University of Lausanne using the $\mathrm{CO}_{2}$-laser fluorination technique. The a nalyses followed the method initially described by Sharp (1990); the details on the procedure in Lausanne are reported by Lacroix and Vennemann (2015). During each a nalytic al session, gamet aliquots in form of small chips of about $1.5-2.5 \mathrm{mg}$ were measured together with the NBS-28 quartz reference material (accepted value 9.64\%, Coplen et al. 1983). The gamet data were corrected to the session value of the NBS-28 quartz and given in conventional

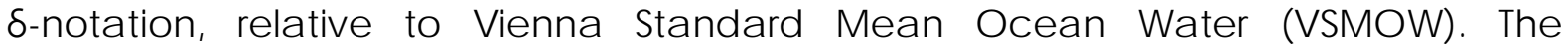
accuracy and uncertainty of NBS-28 quart and the repeatability of the gamet a nalysis a re reported in Table 2.

\section{In situ analysis of oxygen isotopes by SMS}

${ }^{18 \mathrm{O} / 16 \mathrm{O}}$ ratios were measured using the SwissSIMS Cameca IMS $1280 \mathrm{HR}$ instrument at University of Lausanne (Switzerland). Analytical conditions followed Seitz et al. (2017). A $10 \mathrm{kV}{ }^{133} \mathrm{Cs}^{+}$primary Gaussian beam was used with a $1.6-2.1 \mathrm{nA}$ current. This resulted in a typical spot size of $15-25 \mu \mathrm{m}$. The electron flood gun was used to compensate surface charge. The energy slit was $50 \mathrm{eV}$ and secondary ion 
intensities for ${ }^{16} \mathrm{O}$ were typically 1.5 - $1.7 \cdot 10^{9} \mathrm{cps}$. One session (G RT-SPS mount, August 2016) had count rates of $2.1-2.2 \cdot 10^{9} \mathrm{cps}$. A pre-analysis sputtering time of 30s was applied to remove the gold coating, followed by automated secondary beam centring and 20 cycles of $5 \mathrm{~s}$ data acquisition. Oxygen isotope ratios $(18 \mathrm{O} / 16 \mathrm{O})$ are in delta notation ( $\delta^{18} \mathrm{O}$ in $\%$ ) relative to the Vienna Standard Mean Ocean Water (VSMOW). Raw data tables for each session are given in the Supplementary Material 1.

In order to investigate the stability of the matrix effect on the long term, the analytical sessions were distributed over a time window of more than three years. This allows possible effects associated with instrument tuning - performed before each session - to be detected. The mount GRT-GRS was analysed during 3 sessions (April 2016, December 2016, October 2018), the mount GRT-SPS during 4 sessions (August 2016, August 2017, J uly 2018, October 2018) and the mount GRT-AND during 2 sessions (March 2017, J une 2019) (Table 3). Each mount was measured during one a d ditional session (August 2016 for GRT-GRS, Dec ember 2016 for GRT-SPS, December 2016 for GRT-AND) during which UWG2 and two other reference materials of different composition were a nalysed (GRS2 and GRS-J H2 in GRT-GRS, 2B3 and ErrRED in GRT-SPS, 2B3 and 10691 in GRT-AND). These latter measurements were not used to calibrate the matrix correction curves, but they were used as independent data to validate the calculated functions. UWG2 was measured as primary standard to monitor the instrument stability and to correct for the matrix-independent instrumental mass fractionation (IMF). UWG2 analyses bracketed the a nalyses on other materials and were homogenously distributed over the session with a proportion of 1 to 3. Data for the evaluation of the oxygen isotope homogeneity of gamet GRS2 and gamet GRS-JH2 were extracted from the mount GRT-GRS ana lytic al sessions, for a total of 79 spot analyses on 5 grain fragments for GRS2 and 
71 spot analyses on 6 grain fragments for GRS-J H2 (Figure 2). The standard error on the measurements or 'intemal error', also referred to as 'within-spot uncertainty' by Ickert and Stem (2013), is the uncertainty on the mean value of the isotope ratios measured during a single-spot analysis. In the Cameca software, this value corresponds to the standard deviation of the mean (= standard error) of the 20 isotope ratios measured during a single-spot measurement (i.e. 20 cycles of 5 seach, see above). The measured standard errors range between $0.10 \%$ and $0.47 \%$ ( 2 se). An instrumental drift correction was performed only for one session (April 2016) using a linear relation with time based on the linear interpolation of the measurements on the standard UWG 2; no time-rela ted drift occurred during the other sessions.

Data for CAP02 were obtained during three sessions (March 2018, October 2018, J une 2019) for a total of 65 spot a nalyses on 25 different grains (Figure 2). One analysis of the primary standard UWG2 was measured every 3-4 analyses of CAP02 and one analysis of G RS-J H2 every 3-6 a nalyses of CAPO2 to monitor the instrument stability. The standard error on the measurements ranges between $0.11 \%$ and $0.26 \%$ o (2se).

The estimation and correction of the total instrumental mass fractionation during oxygen isotope measurements in gamet standards follows the two-step procedure described in Page et al. (2010) and Martin et al. (2014). (1) For all the measured reference materials, the ${ }^{18} \mathrm{O} /{ }^{16} \mathrm{O}$ ratio was first corrected for IMF by reference to gamet standard UWG2 $\left(\delta^{18} \mathrm{O}=5.80 \%\right.$, Valley et al. 1995) after drift correction, if required. (2) The remaining difference between the corrected values and the laserfluorination values in the gamet reference materia ls is interpreted to be due to differences in the grossular, spessartine and andradite components with respect to UWG2. 


\section{Results and disc ussion}

\section{Major element composition of new reference materials}

Crystal chemical homogeneity was tested using EPMA analyses and the results demonstrate the absence of important heterogeneities in GRS2, GRS-J H2 and CAP02 gamet materials.

GRS2 was a na lysed across 5 fragments of the same grain. The composition of GRS2 is Grs88Sps1 And ${ }_{10} \mathrm{CaTT}_{1}$ (Table 1). The standard deviation calculated for MnO, $\mathrm{FeO}_{\text {tot }}$ and $\mathrm{CaO}$ was $0.06,0.36$ and 0.48 wt $\%$ respectively (2sd). GRS-J H2 was analysed across 5 fragments of the same grain. The composition of GRS2 is $\mathrm{GrS}_{83} \mathrm{Pmp}_{1} \mathrm{Sps}_{2} \mathrm{And}_{13} \mathrm{CaTT}_{1}$ (Table 1). The standard deviation calculated for $\mathrm{MnO}$, $\mathrm{FeO}_{\text {tot, }} \mathrm{CaO}$ and $\mathrm{MgO}$ is $0.04,0.10,0.34$ and 0.04 wt\% respectively (2sd). CAP02 was a nalysed across 23 gra ins. The composition of CAP02 is Grs33Prp ${ }_{40} A \mathrm{Am}_{27} \mathrm{Sps} 1$ (Table 1). The standard deviation calculated for $\mathrm{MnO} \mathrm{FeO}_{\text {tot, }} \mathrm{CaO}$ and $\mathrm{MgO}$ is $0.04,0.60,0.96$ and $1.10 \mathrm{wt} \%$ respectively (2sd).

\section{Oxygen isotope composition and homogeneity of new reference}

\section{materials}

Oxygen isotope composition of GRS2, GRS-J H2 and CAP02 was obtained by laser fluorination (LF). The homogeneity was tested by in situ measurements by SIMS a cross different grains or grain fragments in a way that both core and rim portions of different grain fragments were sampled. The SIMS measurements were corrected for matrix-independent instrumental mass fractionation (IMF) by using the reference material UWG2 (Supplementary Material 1) and the uncertainty on the IMF was 
propagated for each individual spot analysis. The data presented in figure 2 are not corrected for matrix-effect because (1) they were used to calibrate the grossularrelated matrix effect (see below) and (2) such correction(s) would apply a constant shift to the $\delta^{18} \mathrm{O}$ value of each spot, having no effect on the spread of the analyses for each material.

Laser fluorination data for GRS2 were acquired by multiple analyses during two sessions (Table 2). The average value of GRS2 determined by LF a nalysis is $8.01 \pm$ $0.10 \%$ ( 2 sd, $n=4)$. GRS2 homogeneity was tested on 5 different fragments of the same grain mounted in the sample GRT-GRS (see above), for a total of 79 points measured over 4 analytical sessions. Average $\delta^{18} \mathrm{O}$ values obtained from the four sessions are $12.58 \pm 0.60 \%$ o, $11.48 \pm 0.59 \%$ o, $11.30 \pm 0.31 \%$ o and $11.07 \pm 0.38 \%$ o (2sd) (Figure 2). The repeatability of the primary standard UWG2 during the sessions was $0.36,0.25,0.25$ and $0.31 \%$ o respectively. The last three sessions show results that overlap within uncertainty, while the average result of the first session is signific antly higher. The repeatability within each session is consistent and within $0.60 \%$ (2sd), which is nota bly higher than that of standards UWG 2.

La ser fluorination data for GRS-J H2 were a cquired by multiple a nalyses duning one session (Table 2). The average value of GRS-J H2 determined by LF analysis is $18.70 \pm 0.08 \%$ o (2sd, $n=2$ ). GRS-J H2 homogeneity was tested on 5 different grain fragments mounted in the sample GRT-GRS (see above), for a total of 71 points measured over 4 analytical sessions. Average $\delta^{18} \mathrm{O}$ values obtained from the four sessions are $22.64 \pm 0.42 \%$ o, $22.30 \pm 0.24 \%$ o, $22.71 \pm 0.34 \%$ o and $22.12 \pm 0.40 \%$ o (2sd) (Figure 2). The repeatability of the primary standard UWG2 during the sessions was $0.36,0.25,0.25$ and $0.31 \%$ orespec tively. The overall average is $22.44 \pm 0.56 \%$ ( 2 sd) .

Laser fluorination data for CAP02 were acquired by multiple a nalyses during one session (Table 2). The average value of CAP02 determined by $\sqcup$ F a nalysis is $4.64 \pm$ 
$0.16 \%$ ( $2 \mathrm{sd}, \mathrm{n}=3$ ). CAP02 homogeneity was tested on 25 different grains, for total of 65 points measured over 3 analytical sessions. Average $\delta^{18} \mathrm{O}$ values obtained from the three sessions are $5.95 \pm 0.41 \%$, $5.53 \pm 0.46 \%$ o and $5.67 \pm 0.44 \%$ o (2sd) (Figure 2 ). The repeatability of the primary standard UWG2 during the sessions was $0.54,0.26$ and $0.29 \%$ respectively. The overa ll average is $5.72 \pm 0.58 \%$ o ( $2 \mathrm{sd}$ ).

\section{Matrix effect}

For this study, the measured matrix-dependent instrumental bias (matrix effect) has been correlated with the gamet end-member proportions of grossular, andradite and spessartine (Figure 3). Reference materials for spessartine and andradite were first corrected for the ubiquitous grossular effect. This is in line with the previous study by Martin et al. (2014) and to what done by Ickert and Stem (2013) to evaluate a possible matrix effect related to $\mathrm{Mg}$ content, and relies on the assumption that the grossular matrix correction rema ins constant despite changes in $\mathrm{Mn}$ and $\mathrm{Fe}$ in the investigated gamet sa mples.

To examine possible matrix effects related to Alm and Prp components, the residuals about the calibration curve for grossular were plotted against Alm, Prp and Mg\# for reference materials with Sps and And $<5 \%$, in order to minimize the effect of these components. Unlike grossular, andradite and spessartine, almandine and pyrope show no significant systematic bias and therefore no calibration curve is given for these components (Figure 4).

The repeatability of the primary standard UWG2 over a session was between $0.24 \%$ and $0.48 \%$ o ( $2 \mathrm{sd}$ ). For each curve, the average residual (i.e. the average of the absolute differences between the estimated values and the corresponding observed values) is reported. This value is significant (i.e. up to 0.31) and should be 
propagated when the final uncertainty on measurements of natural samples is calculated.

Grossular: Instrument bias correlates with the grossular content in Al-rich gamet and appears to be approximately linear for compositions of Grs $=0-35 \%$. However, a second degree polynomial relationship can better fit the correlation over the complete range (Figure 3a), in a greement with previous studies (e.g., Page et al. 2010; Martin et al. 2014). The similarity in the measured values in each reference material over different sessions demonstrates that the grossular component causes a bias that is reproducible over time within analytical uncertainty. The curve that fits all data points obtained across different sessions is given by the equation $\left(R^{2}=0.97\right.$, a verage residual $\left.=0.28\right)$ (Figure $3 a$ )

$$
\operatorname{Bias}(\mathrm{Grs})=-3.32 \mathrm{Grs}^{2}+8.31 \mathrm{Grs}-1.08
$$

According to the measurements, the maximum bias $(3.4-4.1 \%$ ) is found for reference materials with Grs $=84-86 \%$ (GRS-J H2, 10691); the bias for Grs $=88 \%$ (GRS2) is found to be slightly lower, i.e. 3.0 - 3.5\%o. The GRS2 value obtained during the session of April 2016 shows a signific antly higher bias with respect to the other sessions. This reference material was measured again for testing in August 2017 and the result is in agreement with the results obtained in December 2016 and October 2018. The polynomial predicts increasing bias from $3.4 \%$ to $3.7 \%$ with grossular content from $80 \%$ to $90 \%$. The second order polynomial fit reproduces within the uncertainty the measured biases for GRS-J H2, 10691 (Grs = $84-86 \%$ ), while it overestimates the bias for higher grossular content. The use of two high-grossular reference materials in addition to UWG 2 is strongly recommended for analysing gamet with Grs $=80$ - 100. GRS-J H2 was analysed in different mounts over various 
sessions (from April 2016 to J une 2019) as secondary standard and the results have been used to test the accuracy of Equation 1 and are reported in Figure 3a.

Andradite: Measurements on andradite reference materials have first been corrected for grossular matrix effect using Equation 1. The fit of the data after correction is close to linear, but the best fit is a second degree polynomial with equation $\left(R^{2}=0.99\right.$, a verage residual $\left.=0.31\right)$ (Figure $\left.3 b\right)$ :

$$
\operatorname{Bias}(\text { And })=1.85 \mathrm{And}^{2}+6.07 \mathrm{And}-0.02
$$

The matrix effect increases with increasing andradite content up to $7.7 \%$ o for And $=99 \%(A N D-R G)$. The interpolated curve overestimates of $\sim 0.5 \%$ o the bias measured for And $=23 \%(92 \mathrm{~W} 2)$ and underestimates of $\sim 0.5 \%$ o the bias mea sured for And $_{50}$ (LEW10). The correction is within the typical uncertainty of the measurements $(<0.3 \%$ ) for And $=0-5 \%$ while it becomes significant for higher andradite contents.

Spessartine: Measurements on spessartine reference materia ls have first been corrected for grossular matrix effect using Equation 1. The measured values in each reference material over different sessions show a variation larger than the a nalytical error between the first session (August 2016) and the following three sessions (August 2017, J uly 2018 and October 2018). This ma trix effect va riation can be attributed to a difference in count rates among the session of August 2016 (2.1 - $\left.2.2 \cdot 10^{9} \mathrm{cps}\right)$ and the other sessions ( $\left.1.7 \cdot 10^{9} \mathrm{cps}\right)$. Two polynomials are calculated for the session of August 2016 (Equation 3a, $\mathrm{R}^{2}>0.99$, average residual $=0.06$ ) and of August 2017, J uly 2018 and October 2018 (Equation $3 b, R^{2}=0.91$, a verage residual $=0.18$ ): 


$$
\begin{aligned}
& \operatorname{Bias}(\mathrm{Sps})=-2.21 \mathrm{Sps}^{2}+4.42 \mathrm{Sps}-0.05 \\
& \operatorname{Bias}(\mathrm{Sps})=-1.94 \mathrm{Sps}^{2}+2.87 \mathrm{Sps}-0.03
\end{aligned}
$$

For Sps $<10 \%$ a difference $<0.1 \%$ is observed a mong the two curves and the matrix effect is within the typical uncertainty of the measurements $(<0.3 \%$ ). The variation between the two different curves increases with increasing spessartine content up to $>2.0 \%$ o for GRT-1A (Sps $=88 \%$, Figure $3 \mathrm{c}$ ). For this reason, it is not possible to define a unique, valid correction function. Considering the poor repeatability of spessartine related matrix effect, we recommend that at least two reference materials bracketing the composition of the unknown material should be used when measuring gamet with spessartine content above $20 \%$ to produce accurate results.

When gamet of unknown oxygen isotope composition are analysed, the precision on each analysis must take into account (1) the intemal error or 'withinspot uncertainty' of the analysis, (2) the uncertainty on the primary standard (i.e. UWG2) during the specific a nalytical session and (3) the uncertainty on the matrix correction(s). The final $\delta^{18} \mathrm{O}$ of an a nalysis is

$$
\delta^{18} \mathrm{O}_{\text {final }}=\delta^{18} \mathrm{O}_{\text {measured }}-\mathrm{IMF}-\text { Bias }
$$

where $\delta^{18} \mathrm{O}$ measured is the row value of the analysis, with the associated intemal error, IMF is the matrix-independent mass fractionation, the uncertainty of which is that on the primary standard used for the IMF calculation, and Bias is the matrix effect for a given composition, associated to the uncertainty on the calibration. Hence, the final uncertainty on the sum is found as the sum of the uncertainties propagated in quadratic (i.e. the square root of the sum of the squared uncertainties on the single components). 


\section{Variability of matrix bias calibrations}

The observed matrix effect for $\mathrm{Grs}<50 \%$ agrees within $0.1 \%$ with the one described by Ickert and Stem (2013) (determined using a Cameca IMS 1280 instrument at the University of Alberta, Canada), and within $0.3 \%$ with the ones described by Page et al. (2010) (determined using a Cameca IMS 1280 multicollector ion mic roprobe at the University of Wisconsin, Madison), by Martin et al. (2014) (determined using a SHRIMP-SI at the Australian National University) and by Raimondo et al. (2012) (determined using a Cameca IMS 1280 multi-collector ion mic roprobe at the University of Westem Austra lia ). For Grs $>50 \%$, the observed matrix effect is up to $1 \%$ larger than the one described by Page et al. (2010), Ickert and Stem (2013) and Raimondo et al. (2012), and up to 3\%o larger than the one described by Martin et al. (2014) (Figure 3a). It is important to note that Page et al. (2010) and Raimondo et al. (2012) provide a correction based on the combination of grossular + uvarovite $\left(\mathrm{Ca}_{3} \mathrm{Cr}_{2} \mathrm{Si}_{3} \mathrm{O}_{12}\right)$ content, but the latter never exceed $1 \%$ in the reference materials used in this study, resulting in insignific ant bias. Ickert and Stem (2013) propose a correction based on $\mathrm{Ca} /\left(\mathrm{Mg}+\mathrm{Fe}^{2+}+\mathrm{Ca}\right)$ instead of gamet endmembers; in absence of $\mathrm{Mn}, \mathrm{Fe}^{3+}, \mathrm{Cr}^{3+}$ or $\mathrm{Ti}^{4+}$, this corresponds to the grossular component. Hence, the matrix correction for oxygen isotope measurements in gamet due to grossular content is remarkably robust and reproducible across different instruments and laboratories up to $\mathrm{Grs}=50 \%$. For gamet with higher grossular content significant variations are observed in the shape and maximum value of the curve and thus individual calibrations are required with every instrument. Part of this discrepancy is possibly due to the paucity of reference material in the range Grs $=40-80 \%$, which would better define the shape of the curve. 
The observed andradite matrix effect is close in trend and amplitude to the one reported by Martin et al. (2014) (Figure 3b). Page et al. (2010) did not treat each component separately, but the bias observed for high-And, low-Grs gamet LEW2 (And ${ }_{91} \mathrm{GrS}_{6} \mathrm{Alm} \mathrm{Im}_{3}$, bias $=7.1 \%$ ) is in agreement with this study (average bias for LEW2 = 6.5\%o, Table 3). Despite the andradite matrix correction being the most significant (up to $-8 \%$ ), no significant variation have been observed using two different instruments (Cameca 1280 vs SHRIMP).

The observed spessartine matrix effect is shown to vary significantly over different analytical sessions on the SwissSIMS instrument and it differs from the one described by Martin et al. (2014) using a SHRIMP instrument (Figure 3c). This makes the matrix correction for spessartine impossible to predict within useful repeatability and demands that analyses of spessartine rich gamet be always run a ga inst multiple reference material.

No significant matrix effect associated to the almandine and pyrope components was observed (Figure 4). This result is consistent with the data of Ickert and Stem (2013). Ickert and Stem (2013) showed that the matrix effect associated with $\mathrm{Mg}$ in gamet is negligible for an energy window of $50 \mathrm{eV}$ (i.e. that used in this study), but becomes visible by narrowing the energy window, i.e. to $20 \mathrm{eV}$.

\section{Conclusions}

Oxygen isotope measurements of three new gamet reference materials GRS2, GRS-JH2 and CAP02 are presented. The average $\delta^{180}$ values were characterised by laser fluorination and the homogeneity was tested with in situ measurements by SIMS. The average $\delta^{18} \mathrm{O}$ values determined by laser fluorination are GRS2 $=8.01 \pm 0.10 \%$, GRS-J H2 $=18.70 \pm 0.08 \%$ o a nd CAPO2 $=4.64 \pm 0.16 \%$ o (2sd). 
The repeatability within each session of SIMS a nalyses is $0.30-0.60 \%$, $0.24-0.42 \%$ o and $0.40-0.46 \%$ (2sd) respectively. GRS2, GRS-JH2 and CAP02 are suitable as reference materia Is for SIMS a na lysis of grossular rich ga met.

The matrix effect for oxygen isotope analysis in gamet by Cameca IMS $1280 \mathrm{HR}$ at the SwissSIMS laboratory is confimed to be correlated to the grossular, andradite and spessartine component abundance by a second degree polynomial. Such bias can be corrected using empincally detemined calibration curves, given that the relative abundance of the three end-members in the measured gamet is known. The grossular- and andradite-related matrix effects are found to be reproducible across different sessions and sample mounts, but not across instruments and laboratories for Grs $>50 \%$. The spessartine-related matrix effect is not reproducible across different sessions or instruments. Hence, the use of two secondary standards that compositionally bracket the unknown sample is highly recommended in order to accurately correct the ${ }^{18} \mathrm{O} /{ }^{16} \mathrm{O}$ measurements, especially for gamet with Sps > 10\% and/or Grs > 50\%.

\section{Acknowledgements}

We thank Pierre Lanari for the assistance during EPMA analytical sessions and Jörg Hemann for donating gamet samples. We thank the two anonymous reviewers whose comments helped improve and clarify this manuscript. This work was supported by the Swiss National Science Foundation [Project N. 200021_166280].

\section{References}

Brouwer F.M., Bumi T., Engi M. and Berger A. (2005)

Eclogite relics in the Central Alps: PT-evolution, Lu-Hf ages, and implications for formation of tectonic mélange zones. Schweizenische Mineralogische und Petrographisc he Mitteilungen, 85, 147-174.

Chamberlain C.P. and Conrad M.E. (1991) 
Oxygen isotope zoning in gamet. Science, 254, 403-406.

Coplen T.B., Kendall C. and Hopple J . (1983)

Comparison of stable isotope reference samples. Nature, 302, 236-238.

DeerW., Howie R and Zussman J . (1992)

An introduction to the rock-forming minerals. Longman Scientific and Technology (London).

ElerJ .M., Graham C. and Valley J.W. (1997)

SIMS analysis of oxygen isotopes: matrix effects in complex minerals and glasses. Chemic al Geology, 138, 221-244.

Enic o J.C., Bames J.D., Stric kland A. and Valley J.W. (2013)

Oxygen isotope zoning in gamets from Franciscan eclogite blocks: evidence for rock-buffered fluid interaction in the mantle wedge. Contributions to Mineralogy and Petrology, 166, 1161-1176.

Gonzaga RG., Lowry D., Jacob D.E., LeRoex A., Sc hulze D. and Menzies M.A. (2010)

Ec log ites and ga met pyroxenites: Simila rities a nd differences. Joumal of Volcanology and Geothemal Research, Making and Breaking the Arc: a volume in honour of Professor J ohn Gamble, 190, 235-247.

Ic kert RB. and Stem R.A. (2013)

Matrix Corrections and Error Ana lysis in High-Prec ision SIMS ${ }^{18} \mathrm{O} /{ }^{16} \mathrm{O}$ Mea surements of C a-M g-F e Gamet. Geostandards and Geoanalytical Research, 37, 429-448.

Kita N.T., Ushikubo T., Fu B. and Valley J.W. (2009)

High precision SIMS oxygen isotope analysis and the effect of sample topography. Chemic al Geology, 264, 43-57.

Kohn M.J . and Valley J.W. (1998)

Effects of cation substitutions in gamet and pyroxene on equilibrium oxygen isotope fractionations. Joumal of Metamomhic Geology, 16, 625-639.

Lacroix B. and Vennemann T. (2015)

Empirical calibration of the oxygen isotope fractionation between quartz and $\mathrm{Fe}-$ Mg-c hlorite. Geoc himic a et Cosmochimica Acta, 149, 21-31.

Martin LA., Rubatto D., Crépisson C., Hemann J., Putlitz B. and Vitale-Brovarone A. (2014)

Gamet oxygen analysis by SHRIMP-SI: Matrix corrections and application to highpressure metasomatic rocks from Alpine Corsica. Chemical geology, 374, 25-36.

Page F.Z, Essene E.J ., Mukasa S.B. and Valley J.W. (2013)

A gamet-zirc on oxygen isotope record of subduction and exhumation fluids from the Francisc a n Complex, Ca lifomia . J oumal of Petrology, 55, 103-131.

Page F.Z, Kita N.T. and Valley J.W. (2010)

lon microprobe analysis of oxygen isotopes in gamets of complex chemistry. Chemical Geology, 270, 9-19.

Peres P., Kita N.T., Valley J.W., Femandes F. and Sc huhmacher M. (2013)

New sample holder geometry for high precision isotope analyses. Surface and Interface Analysis, 45, 553-556.

Quinn RJ ., Kitajima K., Nakashima D., Spic uzza M.J . and Valley J .W. (2017)

Oxygen isotope themometry using quartz inclusions in gamet. Joumal of Metamorphic Geology, 35, 231-252.

Raimondo T., Clark C., Hand M., Cliff J . and Hamis C. (2012)

High-resolution geochemical record of fluid-rock interaction in a mid-crustal shear zone: a comparative study of major element and oxygen isotope transport in gamet. J oumal of Metamomhic Geology, 30, 255-280.

Regier M., Miškovic A., Ickert RB., Pearson D.G., Stachel T., Stem R.A. and Kopylova M. (2018) 
An oxygen isotope test for the origin of Archean mantle roots. Geochemical Perspectives Letters, 9, 6-10.

Riciputi LR, Paterson B.A. and Ripperdan RL (1998)

Mea surement of light sta ble isotope ratios by SIMS: Matrix effects for oxygen, carbon, and sulfur isotopes in minerals. Intemational J oumal of Mass Spectrometry, 178, 81112.

Rubatto D. and Angiboust S. (2015)

Oxygen isotope record of oceanic and high-pressure metasomatism: a P-T-timefluid path for the Monviso eclogites (Italy). Contributions to mineralogy and petrology, 170, 44.

Seitz S., Baumgartner LP., Bouvier A.-S., Putlitz B. and Vennemann T. (2017)

Quartz reference materials for oxygen isotope a nalysis by SIMS. Geostandards and Geoanalytical Research, 41, 69-75.

Sharp ZD. (1990)

A laser-based microanalytical method for the in situ determination of oxygen isotope ratios of silic ates and oxides. Geochimica et Cosmochimica Acta, 54, 13531357.

Shimura T. and Kemp A.I.S. (2015)

Tetrahedral plot diagram: A geometrical solution for quatemary systems. American Mineralogist, 100, 2545-2547.

Urosevic M., Nebel O., Padrón-Navarta J .A. and Rubatto D. (2018)

Assessment of $\mathrm{O}$ and $\mathrm{Fe}$ isotope heterogeneity in gamet from Kakanui (New Zea land) and Erongo (Namibia). European joumal of mineralogy, 30, 695-710.

Valley J.W., Kitchen N., Kohn M.J ., Niendorf C.R. and Spic uzza M.J . (1995)

UWG -2, a gamet standard for oxygen isotope ratios: stra tegies for high precision and accuracy with laser heating. Geochimica et Cosmochimica Acta, 59, 5223-5231.

Vielzeuf D., Champenois M., Valley J.W., Brunet F. and DevidaI J .L (2005a)

SIMS analyses of oxygen isotopes: matrix effects in $\mathrm{Fe}-\mathrm{Mg}-\mathrm{Ca}$ gamets. Chemical Geology, 223, 208-226.

Vielzeuf D., Vesc hambre M. and BrunetF. (2005b)

Oxygen isotope heterogeneities and diffusion profile in composite metamorphicmagmatic gamets from the Pyrenees. American Mineralogist, 90, 463-472. 
Figures and Tables

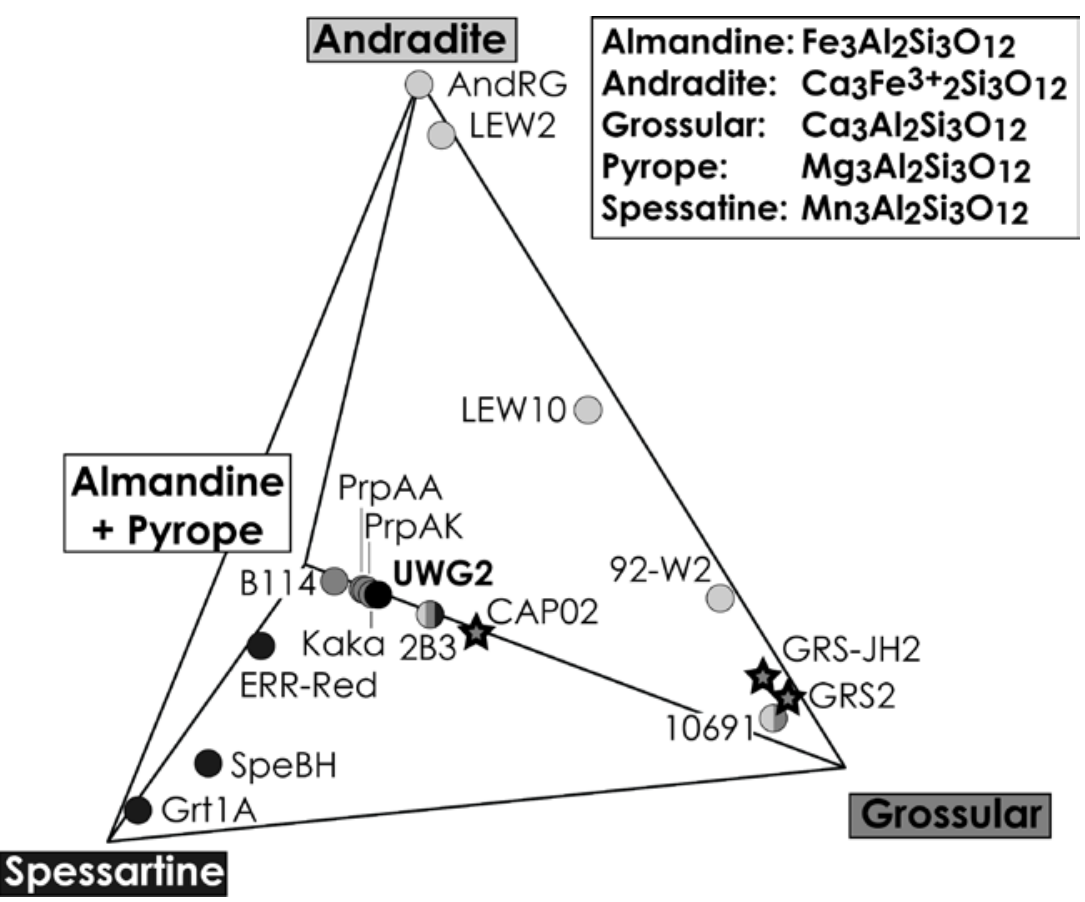

Figure 1. Tetrahedral plot (constructed with the Excel spreadsheet by Shimura and Kemp 2015) showing the composition of reference gamet samples used in this study. Stars represent the reference materials characterized in this study; dots represent gamet samples characterized in previous studies (see text for details). Symbol fill colours show for which calibration (i.e. grossular, andradite or spessartine matrix effect comection) each of the material was used. 


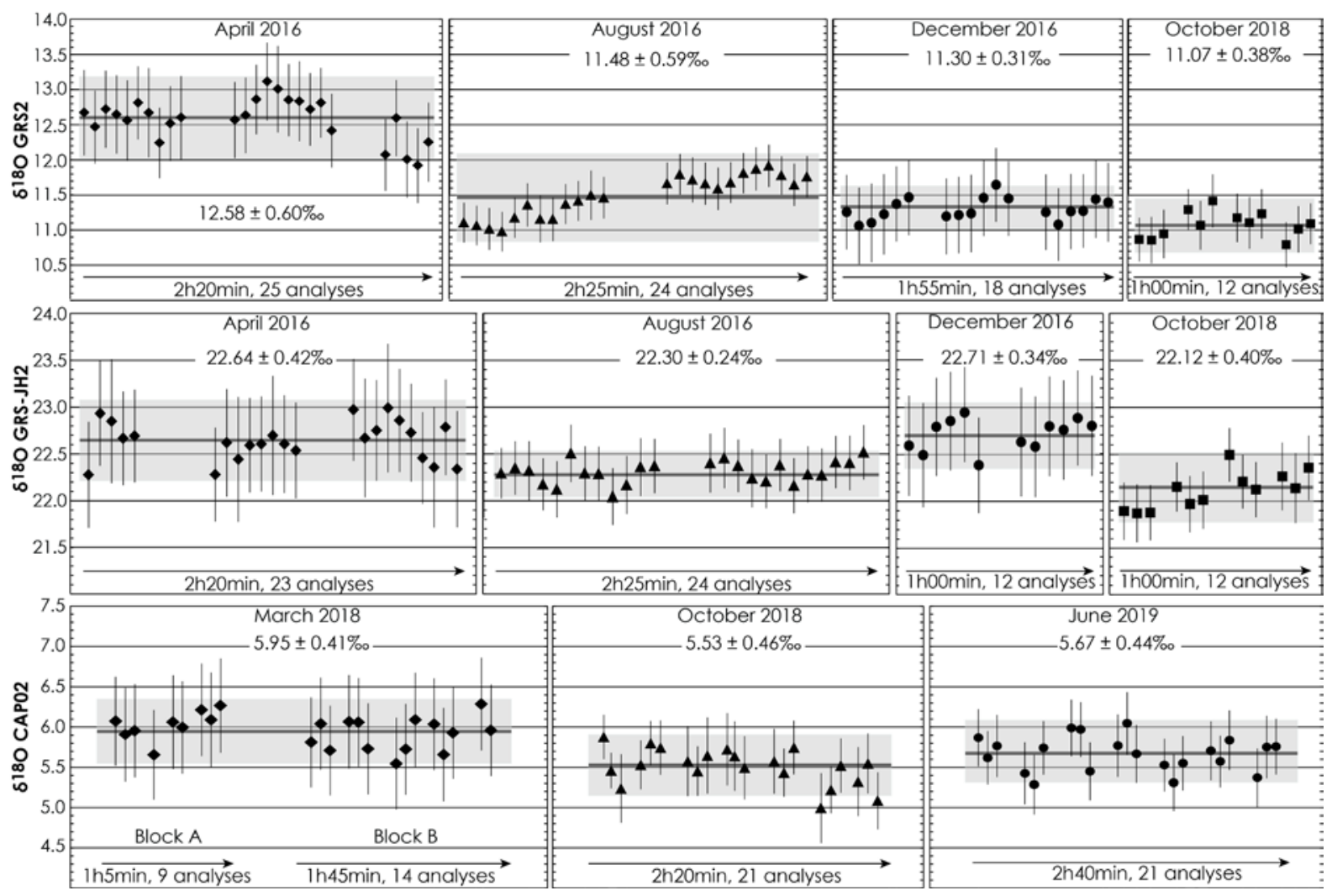

Figure 2. $\delta^{180}$ SMS values for CAP02 (a), GRS2 (b) and GRS-JH2 (c). The data were corrected for IMF using UWG2 gamet as primary standard. The uncertainty shown for a single analysis (2sd) combines the measurement standard emor and the uncertainty on the matrix-independent IMF. Average values for each session are reported (grey lines) with standard deviations (2sd) for each session (shaded bands). 

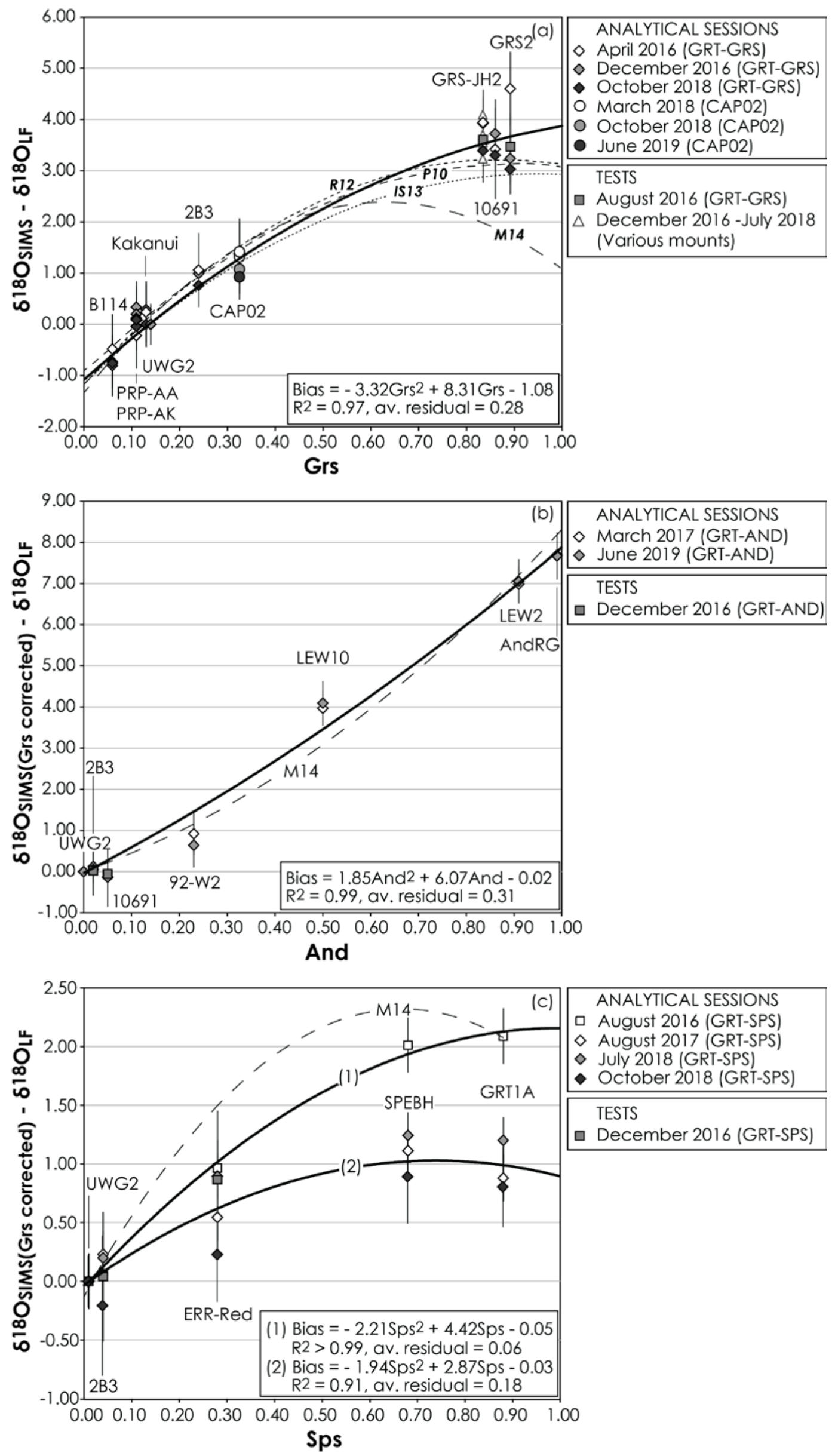
Figure 3. Matrix effect plotted as a function of gamet end-member proportion for (a) grossular, (b) andradite and (c) spessartine. Emor bars represent the standard emors combined with the uncertainty on the IMF ( $\pm 2 s d)$. The solid lines are bestfit regressions through the measurements from this study; dashed lines are regressions from Page et al. (2010) (P10), Raimondo et al. (2012) (R12), Ic kert and Stem (2013) (IS13) and Martin et al. (2014) (M14). Data marked as "TEST" were not used for the regression, but they were used as independent constrains to test the validity of the calculated functions. Data shown in panels (b) and (c) have been first corrected for any grossular effect 

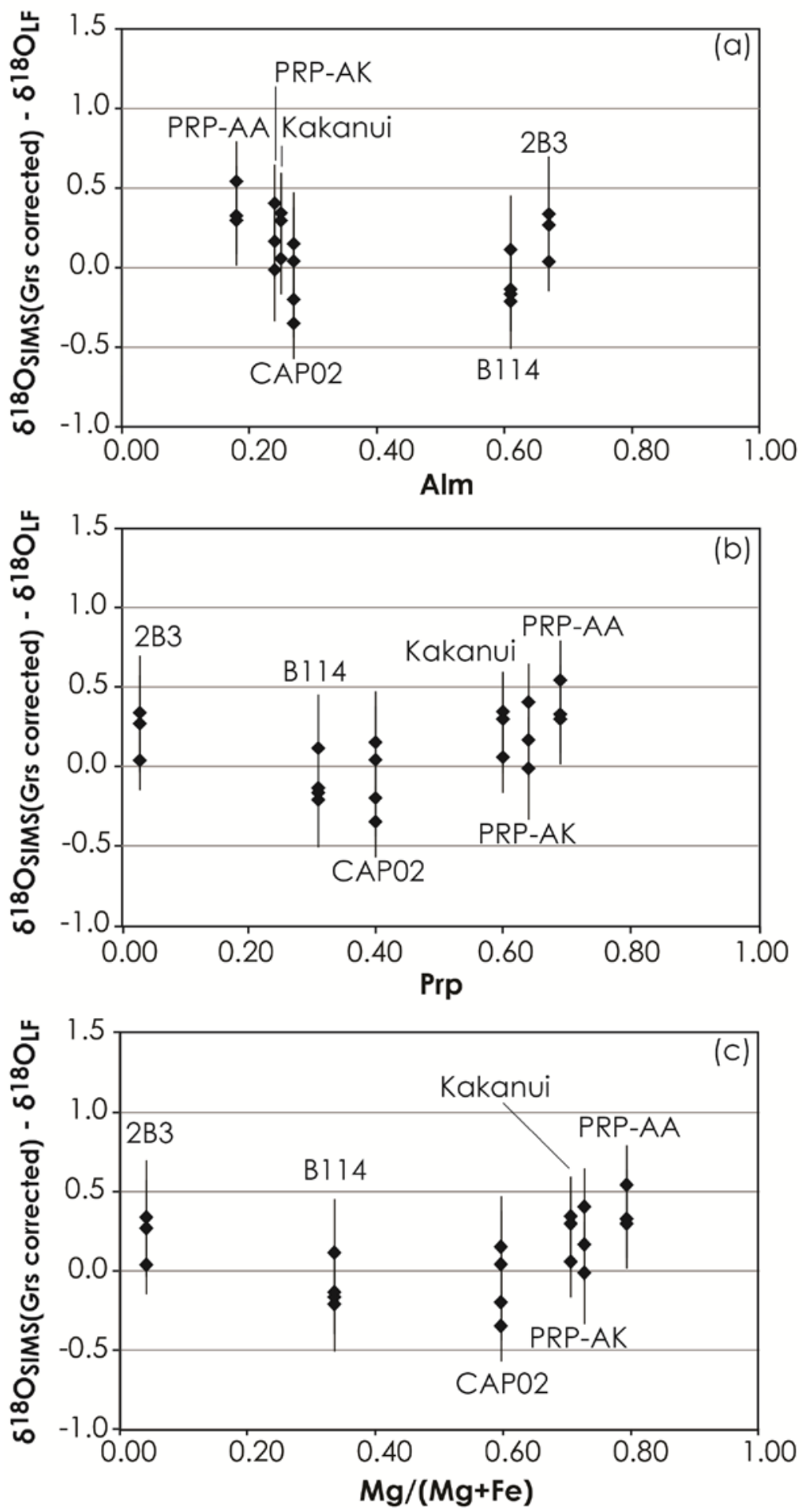

Figure 4. Testing the matrix effect of Fe and Mg content The matrix bias $\left(\delta^{18}\right)_{\text {sims }}$ $d^{18} \mathrm{O}_{\text {tr) }}$ after the Grs comection for each sample and session are plotted against Alm (a), Prp (b) and Mg\# (c). Only gamet reference materials with And < 10\% and Sps < 5\% are considered. Enor bars represent the standard emors combined with the unc ertainty on the IMF ( $\pm 2 \mathrm{2sd})$. No signific ant comelation is observed. 
Table 1. Major element composition of gamet samples GRS2 (number of analyses = 52), GRS-J H2 (number of analyses $=50$ ) and CAPO2 (number of analyses $=139$ ).

\begin{tabular}{|c|c|c|c|c|c|c|}
\hline & \multicolumn{2}{|c|}{ GRS2 } & \multicolumn{2}{|c|}{ GRSJ HD } & \multicolumn{2}{|c|}{ CAP02 } \\
\hline & $\begin{array}{r}\text { Av. Oxide } \\
\text { weight } \%\end{array}$ & $2 s d$ & $\begin{array}{r}\text { Av. Oxide } \\
\text { weight } \%\end{array}$ & $2 s d$ & $\begin{array}{l}\text { Av. Oxide } \\
\text { weight } \%\end{array}$ & $2 s d$ \\
\hline $\mathrm{SiO}_{2}$ & 38.32 & 0.46 & 39.00 & 0.34 & 40.71 & 0.62 \\
\hline $\mathrm{Al}_{2} \mathrm{O}_{3}$ & 20.73 & 0.76 & 19.38 & 0.30 & 22.79 & 0.44 \\
\hline $\mathrm{TiO}_{2}$ & 0.20 & 0.08 & 0.41 & 0.08 & 0.07 & 0.04 \\
\hline $\mathrm{MgO}$ & 0.06 & 0.04 & 0.14 & 0.04 & 10.81 & 1.10 \\
\hline $\mathrm{FeO}$ & 2.99 & 0.36 & 4.41 & 0.10 & 13.24 & 0.60 \\
\hline $\mathrm{MnO}$ & 0.24 & 0.06 & 0.77 & 0.04 & 0.27 & 0.04 \\
\hline $\mathrm{CaO}$ & 36.86 & 0.48 & 35.83 & 0.34 & 12.37 & 0.96 \\
\hline $\mathrm{Cr}_{2} \mathrm{O}_{3}$ & 0.01 & 0.02 & 0.01 & 0.02 & na & na \\
\hline Total & 99.41 & 0.96 & 99.94 & 0.54 & 100.27 & 1.74 \\
\hline & $\begin{array}{c}\text { Cations, } \\
\text { charge } \\
\text { balance }\end{array}$ & & $\begin{array}{r}\text { Cations, } \\
\text { charge } \\
\text { balance }\end{array}$ & & $\begin{array}{r}\text { Cations, } \\
\text { charge } \\
\text { balance }\end{array}$ & \\
\hline Si & 2.91 & & 2.97 & & 3.01 & \\
\hline AlvI & 1.86 & & 1.74 & & 1.98 & \\
\hline $\mathrm{Ti}$ & 0.01 & & 0.02 & & 0.00 & \\
\hline $\mathrm{Fe}^{3+}$ & 0.19 & & 0.28 & & 0.02 & \\
\hline $\mathrm{Fe}^{2+}$ & 0.00 & & 0.01 & & 0.80 & \\
\hline $\mathrm{Mn}$ & 0.02 & & 0.05 & & 0.02 & \\
\hline $\mathrm{Mg}$ & 0.01 & & 0.02 & & 1.19 & \\
\hline $\mathrm{Ca}$ & 3.00 & & 2.92 & & 0.98 & \\
\hline & $\begin{array}{r}\text { End } \\
\text { member } \\
(\%)\end{array}$ & $2 s d$ & $\begin{array}{r}\text { End } \\
\text { member } \\
(\%)\end{array}$ & $2 s d$ & $\begin{array}{r}\text { End } \\
\text { member } \\
(\%)\end{array}$ & $2 s d$ \\
\hline Alm & 0.00 & 0.00 & 0.43 & 0.96 & 26.87 & 1.56 \\
\hline Prp & 0.22 & 0.18 & 0.54 & 0.12 & 39.79 & 3.02 \\
\hline Grs & 88.33 & 1.28 & 83.31 & 0.70 & 32.46 & 2.92 \\
\hline Sps & 0.53 & 0.16 & 1.65 & 0.08 & 0.57 & 0.10 \\
\hline And & 10.37 & 1.08 & 12.94 & 1.54 & 0.24 & 0.60 \\
\hline $\mathrm{Ca}-\mathrm{Ti}$ & 0.55 & 0.24 & 1.14 & 0.20 & 0.06 & 0.04 \\
\hline
\end{tabular}


Table 2. Oxygen isotope composition of gamet samples GRS2, GRS J H2 and CAP02 determined by $\mathrm{CO}_{2}$ laser fluorination analysis.

\begin{tabular}{|c|c|c|c|}
\hline & $\delta^{180}(\% \circ)$ comected & Reference material & $\delta^{180}$ raw (\%o)* \\
\hline \multicolumn{4}{|l|}{ GRS2 } \\
\hline \multicolumn{4}{|l|}{ Session 03.07.2012 } \\
\hline analysis 1 & 8.08 & NBS-28 quartz & $9.39 \pm 0.10(n=4)(2 s d)$ \\
\hline analysis 2 & 8.03 & & \\
\hline Average session 1 & $8.05 \pm 0.06(2 \mathrm{sd})$ & & \\
\hline \multicolumn{4}{|l|}{ Session 11.07.2012 } \\
\hline analysis 3 & 8.00 & NBS-28 quartz & $9.42 \pm 0.45(n=6)(2 s d)$ \\
\hline analysis 4 & 7.96 & & \\
\hline Average session 2 & $7.98 \pm 0.06(2 \mathrm{sd})$ & & \\
\hline Average GRS2 & $8.01 \pm 0.10(2 \mathrm{sd})$ & & \\
\hline \multicolumn{4}{|l|}{ GRSJH2 } \\
\hline \multicolumn{4}{|l|}{ Session 21.02.2017 } \\
\hline analysis 1 & 18.73 & NBS-28 quartz & $9.66 \pm 0.04(n=4)(2 s d)$ \\
\hline a nalysis 2 & 18.68 & & \\
\hline Average GRS-J H2 & $18.70 \pm 0.08(2 \mathrm{sd})$ & & \\
\hline \multicolumn{4}{|l|}{ CAPO2 } \\
\hline \multicolumn{4}{|l|}{ Session 13.06.2019 } \\
\hline analysis 1 & 4.73 & NBS-28 quartz & $9.36 \pm 0.30(n=3)(2 s d)$ \\
\hline analysis 2 & 4.58 & & \\
\hline analysis 3 & 4.62 & & \\
\hline Average CAP02 & $4.64 \pm 0.16(2 \mathrm{sd})$ & & \\
\hline
\end{tabular}

Table 3. Summary of analytical data from gamet reference materials. Data are organized in (1) reference materials used in the grossular comection; (2) reference materials used in the andradite comection; (3) reference materials used in the spessartine comection and (4) Reference materials measured as tests (i.e. not used for the regressions). Within each block, UWG2 is reported as first and the other gamet samples follow in order of increasing grossular. For all the test measurements UWG2 was used as primary standard to correct for the matrix independent IMF but it is not reported. The uncertainty on the IMF corrected $\delta^{18} 0_{\text {sms }}(2 s d)$ accounts for (1) the uncertainty on the average and (2) that on the IMF calculation. 


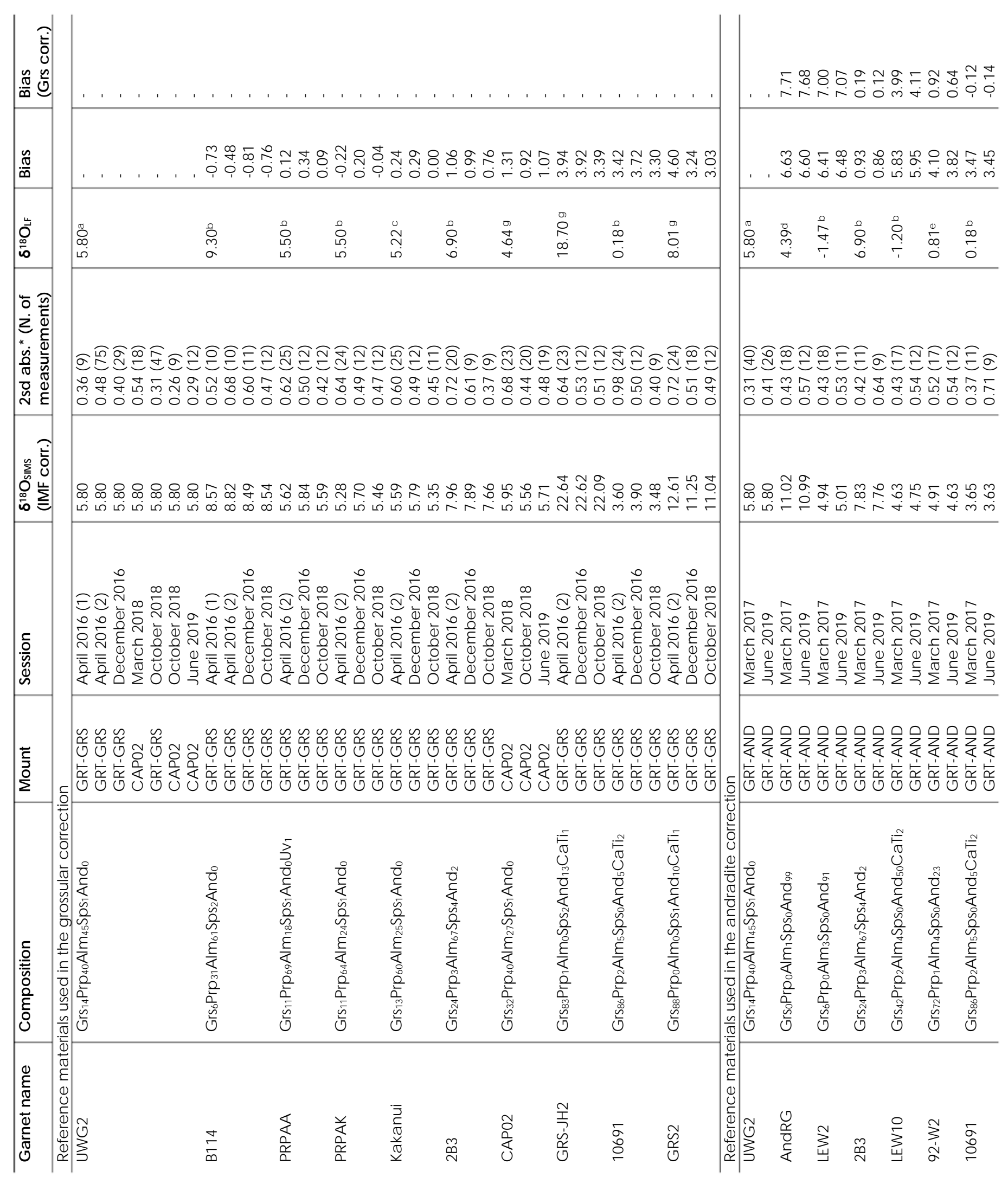




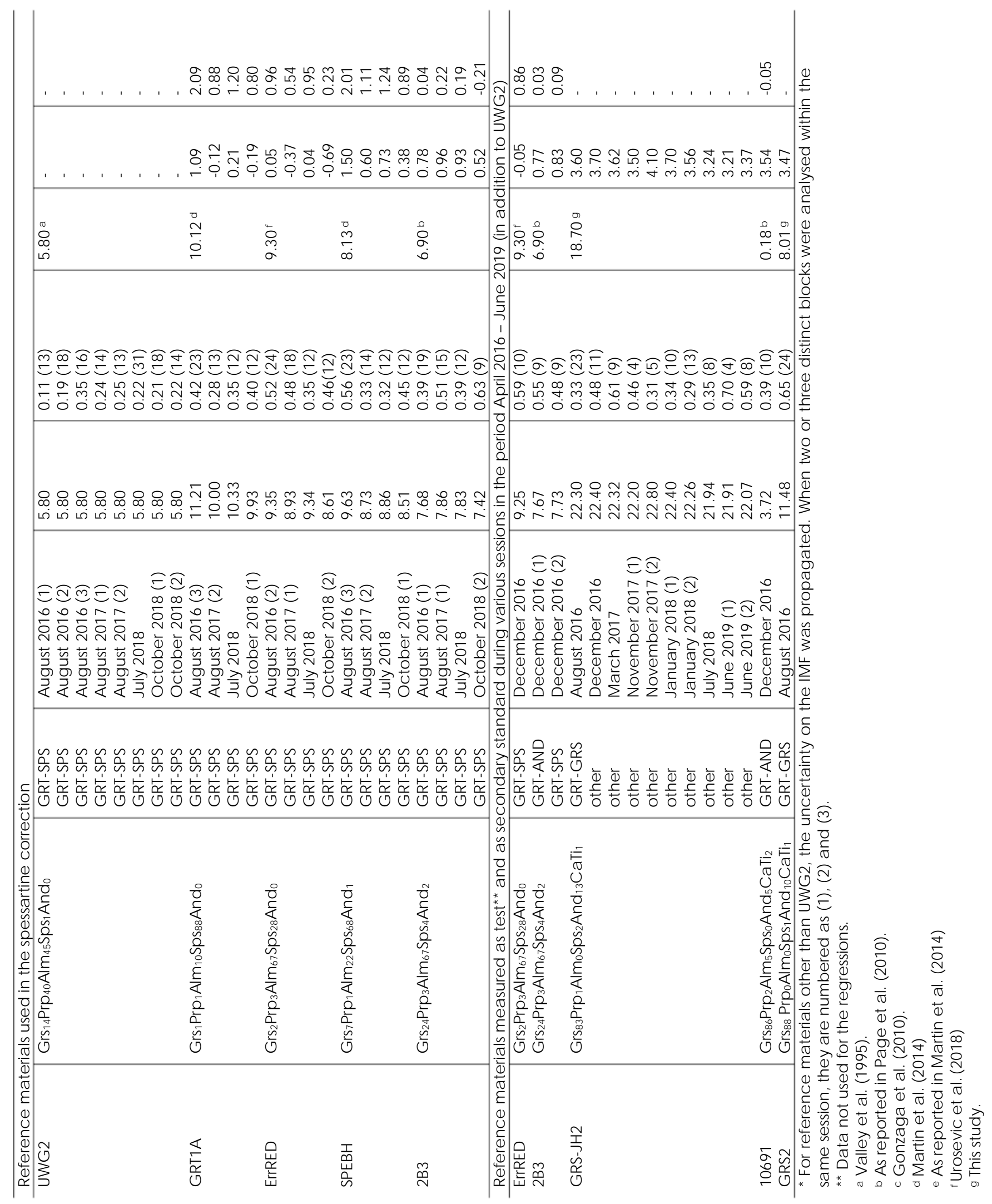

